\title{
Analysis and Forecast of China's Grain Supply and Demand Quality Grade Structural Balance
}

\author{
Bingjun Li, Weiming Yang*, Mengfei Wu \\ College of Information and Management Science, Henan Agricultural University, Zhengzhou, China \\ Email: *yangweiming626@163.com
}

How to cite this paper: $\mathrm{Li}, \mathrm{B}$.J., Yang, W.M. and Wu, M.F. (2018) Analysis and Forecast of China's Grain Supply and Demand Quality Grade Structural Balance. American Journal of Plant Sciences, 9, 1747-1758.

https://doi.org/10.4236/ajps.2018.98127

Received: April 30, 2018

Accepted: July 28, 2018

Published: July 31, 2018

Copyright $\odot 2018$ by authors and Scientific Research Publishing Inc. This work is licensed under the Creative Commons Attribution International License (CC BY 4.0).

http://creativecommons.org/licenses/by/4.0/

\begin{abstract}
Based on the analysis of China's grain production and demand quality grade, this paper uses the non-equidistance GM $(1,1)$ model and the inference algorithm to predict the structural balance of the supply and demand grades of China's four major grain crops. The results show that the supply and demand for wheat, corn and rice can maintain a quantitative balance. While, it's difficult to achieve a quality grade balance in wheat and rice and keep a supply and demand balance in terms of quantity and quality of soybean. Simultaneously, the supply of premium grade corn is greater than the demand. The analysis and prediction results can reflect the existing structural balance matter of grain supply and demand at different quality grades in China, and provide theoretical basis for governments to formulate relevant policies.
\end{abstract}

\section{Keywords}

Quality Grade, Supply-Demand Structure, Non-Equidistance, GM $(1,1)$ Model

\section{Introduction}

According to the Statistical Yearbook, China's grain yield has exceeded 0.6 trillion kilograms for five consecutive years, but the import quantity remained high and have grown year by year. The grain demand has changed from a total shortage to a structural contradiction. The corn, common wheat, and rice in China are surplus, while soybean, strong gluten and weak gluten are seriously insufficient. This shows that the quality of China's grain production can't kept up with the increasing demand for high quality food. Therefore, it is essential to study the structural balance of the grain supply and demand quality grade in China. Previous research on grain supply and demand quality grade mainly fo-

${ }^{\star}$ Corresponding author. 
cuses on the following two aspects. On the one hand, it is about the total quantitative balance of grain supply and demand. Xie [1] predicted the new situation and challenges of grain supply and demand in the new era. $\mathrm{Hu}$ [2] established a grain supply and demand model to study the structural characteristics and spatial distribution of China's grain supply and demand. Gao and Teng [3] [4] analyzed the grain supply and demand relationship and grain security situation in Tibet and Chongqing respectively. Shang [5] analyzed the trends of grain price in the international and domestic markets and their correlation with China's grain supply and demand. On the other hand, many scholars have conducted research on grain quality and safety. Zhu [6] studied the government responsibility system of grain quality and safety. Zhang [7] analyzed the status quo of grain quality safety and evaluated various aspects of grain security. Guo [8] took the improvement of wheat quality as an example to analyze the impact of improved subsidies on grain quality. It can be seen from the previous studies that most scholars analyzed and predicted the total amount of grain supply and demand, qualitatively studied the policy standards of grain quality. There is little or no quantitative research on the supply and demand balance for grain quality grade. In addition, considering the characteristics of grey forecasting for small sample poor information data, this paper divides grain production and consumption into different grades for supply and demand balance research and forecast grain production and demand by grey prediction model. The grey non-equidistant model would make the prediction and analysis results more realistic.

\section{Research Methods}

\subsection{Non-Equidistant GM $(1,1)$ Model}

GM(1,1) model is an important prediction method of the grey system theory. It mines new information based on the limited data of the research object, and expresses the inherent trend and basic law. Since it is suitable for "small sample" and "poor information" uncertain system modeling, it is widely used in industries, agriculture, medicine, geological exploration and other fields. Due to the inaccessibility and lack of data in the grain production and demand, this paper chooses the non-equidistance $\operatorname{GM}(1,1)$ model to predict them, which can make the prediction results more realistic. The modeling mechanism is as follows [9] [10] [11]:

Set the non-negative sequence as $X^{(0)}=\left\{x^{(0)}\left(k_{1}\right), x^{(0)}\left(k_{2}\right), \cdots, x^{(0)}\left(k_{n}\right)\right\}$, if the spacing interva exists $\Delta k_{i}=k_{i}-k_{i-1} \neq c o n s$, then $X^{(0)}$ is called as unequidistant sequence. The accumulative generation sequence of $X^{(0)}$ is $X^{(1)}=\left\{x^{(1)}\left(k_{1}\right), x^{(1)}\left(k_{2}\right), \cdots, x^{(1)}\left(k_{n}\right)\right\}$. Where, $X^{(1)}=\sum_{j=1}^{i} x^{(0)}\left(k_{j}\right) \Delta k_{j}$, $i=1,2, \cdots n$. Establish a GM $(1,1)$ model for acumulative generation sequence $X^{(1)}$. Its whitening differential equation is $\frac{\mathrm{d} x^{(1)}(t)}{\mathrm{d} t}+a x^{(1)}(t)=b$, grey differen- 
tial equation is $x^{(0)}\left(k_{i}\right)+a z^{(1)}\left(k_{i}\right)=b$. Reducing the time response $\hat{x}^{(1)}\left(k_{i}\right)=\left(x^{(1)}-\frac{b}{a}\right) \mathrm{e}^{-a\left(k_{i}-k_{1}\right)}+\frac{b}{a}$, The simulated reduction value of the original sequence can be obtained:

$\hat{x}^{(1)}\left(k_{i}\right)=\frac{\hat{x}\left(k_{i}\right)-\hat{x}\left(k_{i-1}\right)}{\Delta k_{i}}=\frac{1}{\Delta k_{i}}\left(1-\mathrm{e}^{a \Delta k_{i}}\right)\left(x^{(1)}\left(k_{1}\right)-\frac{b}{a}\right) \mathrm{e}^{-a\left(k_{i}-k_{1}\right)}$.

\subsection{Inference Algorithm}

The purpose of grain demand forecasting is to adjust the grain production structure according to the forecast results to achieve a balance between supply and demand. This paper will measure the demand for major grain crops based on the analysis of the consumption characteristics and the prediction of grain demand.

\section{Analysis and Forecast of Grain Supply and Demand Quality Grade}

With the improvement of people's living standards and the richness of material consumption, people's requirements for the quality of grain are getting higher and higher, not only limited to the satisfaction of quantity, but also to the safety, health, appearance and quality of grain products. In the case of equal safety and hygiene, the choice of high-quality grain products has gradually become a new consumer concept and culture. Therefore, this paper divides grain production according to the quality grade standard of China, divides the grain demand grade according to the demand quantity of different purposes of grain, and analyses and predicts the balance of quality grade.

\subsection{Division and Analysis of Grain Production Quality Grade Standards}

According to national standards, wheat's quality grade standard is divided into first grade to fifth grade and substandard in light of the capacity, unsound kernel, impurity content, moisture and color and odor. Details of the grade standard for wheat are shown in Table 1.

Corn's quality grade standard is divided into first grade to fifth grade and substandard according to capacity, unsound kernel, impurity content, moisture and color and odor. The details of the grade standard for corn are shown in Table 2 .

Soybean's quality grade standard is divided into first grade to fifth grade and substandard according to capacity, unsound kernel, impurity content, moisture and color and odor. The details of the grade standard for soybean are shown in Table 3.

The rice is mainly divided into hsien rice and japonica rice. Then the hsien rice is divided into early hsien rice, late hsien rice and indica glutinous rice, the japonica rice is divided into japonica rice and round grain glutinous rice. The 
Table 1. Quality standard of wheat.

\begin{tabular}{|c|c|c|c|c|c|c|}
\hline \multirow[b]{2}{*}{ grade } & \multirow{2}{*}{$\begin{array}{c}\text { capacity } \\
(\mathrm{g} / \mathrm{L})\end{array}$} & \multirow{2}{*}{$\begin{array}{c}\text { Unsound } \\
\text { Kernel (\%) }\end{array}$} & \multicolumn{2}{|c|}{ Impurity (\%) } & \multirow{2}{*}{ Moisture (\%) } & \multirow{2}{*}{$\begin{array}{c}\text { color and } \\
\text { odor }\end{array}$} \\
\hline & & & total & $\begin{array}{l}\text { of which: } \\
\text { minerals }\end{array}$ & & \\
\hline first grade & $\geq 790$ & $\leq 6$ & $\leq 1$ & $\leq 0.5$ & $\leq 12.5$ & normal \\
\hline second grade & $\geq 770$ & $\leq 6$ & $\leq 1$ & $\leq 0.5$ & $\leq 12.5$ & normal \\
\hline third grade & $\geq 750$ & $\leq 8$ & $\leq 1$ & $\leq 0.5$ & $\leq 12.5$ & normal \\
\hline fourth grade & $\geq 730$ & $\leq 8$ & $\leq 1$ & $\leq 0.5$ & $\leq 12.5$ & normal \\
\hline fifth grade & $\geq 710$ & $\leq 10$ & $\leq 1$ & $\leq 0.5$ & $\leq 12.5$ & normal \\
\hline substandard & $<710$ & - & $\leq 1$ & $\leq 0.5$ & $\leq 12.5$ & normal \\
\hline
\end{tabular}

(Note: The date source of Tables 1-4 is National Food and Material Reserve Bureau of China).

Table 2. Quality standard of corn.

\begin{tabular}{cccccc}
\hline grade & capacity $(\mathrm{g} / \mathrm{L})$ & $\begin{array}{c}\text { unsound } \\
\text { kernel }(\%)\end{array}$ & Impurity (\%) & Moisture (\%) & color and odor \\
\hline first grade & $\geq 720$ & $\leq 4$ & $\leq 1$ & $\leq 14$ & normal \\
second grade & $\geq 685$ & $\leq 6$ & $\leq 1$ & $\leq 14$ & normal \\
third grade & $\geq 650$ & $\leq 8$ & $\leq 1$ & $\leq 14$ & normal \\
fourth grade & $\geq 620$ & $\leq 10$ & $\leq 1$ & $\leq 14$ & normal \\
fifth grade & $\geq 590$ & $\leq 15$ & $\leq 1$ & $\leq 14$ & normal \\
substandard & $<590$ & $\leq 15$ & $\leq 1$ & $\leq 14$ & normal \\
\hline
\end{tabular}

Table 3. Quality standard of soybean.

\begin{tabular}{|c|c|c|c|c|c|c|}
\hline \multirow{2}{*}{ grade } & \multirow{2}{*}{$\begin{array}{c}\text { complete } \\
\text { grain rate }(\%)\end{array}$} & \multicolumn{2}{|c|}{ damage rate $(\%)$} & \multirow{2}{*}{$\begin{array}{c}\text { impurity } \\
\text { (\%) }\end{array}$} & \multirow{2}{*}{$\begin{array}{c}\text { moisture } \\
(\%)\end{array}$} & \multirow{2}{*}{$\begin{array}{c}\text { color and } \\
\text { odor }\end{array}$} \\
\hline & & total & $\begin{array}{c}\text { thermal } \\
\text { damage particles }\end{array}$ & & & \\
\hline first grade & $\geq 95$ & $\leq 1$ & $\leq 0.2$ & $\leq 1$ & $\leq 13$ & normal \\
\hline second grade & $\geq 90$ & $\leq 1$ & $\leq 0.2$ & $\leq 1$ & $\leq 13$ & normal \\
\hline third grade & $\geq 85$ & $\leq 1$ & $\leq 0.5$ & $\leq 1$ & $\leq 13$ & normal \\
\hline fourth grade & $\geq 80$ & $\leq 1$ & $\leq 1$ & $\leq 1$ & $\leq 13$ & normal \\
\hline fifth grade & $\geq 75$ & $\leq 1$ & $\leq 3$ & $\leq 1$ & $\leq 13$ & normal \\
\hline substandard & $<75$ & - & - & - & - & normal \\
\hline
\end{tabular}

rice's quality grade standard is divided into first grade to fifth grade substandard according to roughness rate, whole milled rice rate, impurities, moisture, color and odor. The details of the grade standards for rice are shown in Table 4.

According to the quality grade standards of major grain varieties of grain, the data of China Grain Network and China Statistical Yearbook, the grain production 
Table 4. Quality standard of rice.

\begin{tabular}{|c|c|c|c|c|c|c|}
\hline variety & grade & $\begin{array}{l}\text { roughness } \\
\text { rate }(\%)\end{array}$ & $\begin{array}{l}\text { whole milled } \\
\text { rice rate (\%) }\end{array}$ & $\begin{array}{c}\text { impurities } \\
(\%)\end{array}$ & Moisture (\%) & $\begin{array}{c}\text { color and } \\
\text { odor }\end{array}$ \\
\hline \multirow{6}{*}{$\begin{array}{l}\text { early hsien } \\
\text { rice, late } \\
\text { hsien rice } \\
\text { and indica } \\
\text { glutinous rice }\end{array}$} & first grade & $\geq 79$ & $\geq 50$ & $\leq 1$ & $\leq 13.5$ & normal \\
\hline & second grade & $\geq 77$ & $\geq 50$ & $\leq 1$ & $\leq 13.5$ & normal \\
\hline & third grade & $\geq 75$ & $\geq 50$ & $\leq 1$ & $\leq 13.5$ & normal \\
\hline & fourth grade & $\geq 73$ & $\geq 50$ & $\leq 1$ & $\leq 13.5$ & normal \\
\hline & fifth grade & $\geq 71$ & $\geq 50$ & $\leq 1$ & $\leq 13.5$ & normal \\
\hline & substandard & $<71$ & - & - & - & - \\
\hline \multirow{6}{*}{$\begin{array}{l}\text { japonica rice } \\
\text { and round } \\
\text { grain } \\
\text { glutinous } \\
\text { rice }\end{array}$} & first grade & $\geq 81$ & $\geq 60$ & $\leq 1$ & $\leq 14.5$ & normal \\
\hline & second grade & $\geq 79$ & $\geq 60$ & $\leq 1$ & $\leq 14.5$ & normal \\
\hline & third grade & $\geq 77$ & $\geq 60$ & $\leq 1$ & $\leq 14.5$ & normal \\
\hline & fourth grade & $\geq 75$ & $\geq 60$ & $\leq 1$ & $\leq 14.5$ & normal \\
\hline & fifth grade & $\geq 73$ & $\geq 60$ & $\leq 1$ & $\leq 14.5$ & normal \\
\hline & substandard & $<73$ & - & - & - & - \\
\hline
\end{tabular}

quality grades from 2011 to 2017 are summarized in Table 5 (the data of 2012 and 2013 are deleted).

It can be seen from Table 5 that in the overall quality level of grain production in China, except for soybeans, the proportion of medium and above is more than $90 \%$. The first grade quantity of wheat production increased in volatility, and the proportion of total wheat gradually increased from 37\% in 2011 to $43 \%$ in 2017. The number of second-grade and third-grade wheat gradually decreased, the second grade proportion reduced from 35\% in 2011 to $31 \%$ in 2017 and the proportion of third-grade wheat fell from $21 \%$ in 2011 to $16 \%$ in 2017. The proportion of fourth grade wheat fluctuated slightly around $6 \%$. The proportion of the fifth grade reached $7 \%$ in 2015 , and the other years fluctuated slightly around $2 \%$.

The quantity and proportion of first grade corn gradually increased, and the proportion increased from $45 \%$ in 2011 to $71 \%$ in 2017 . The second grade corn declined in small fluctuations, from $39 \%$ in 2011 to $21.9 \%$ in 2017 . The quantity and proportion of corn with a quality grade of three to five all decreased fluctuately.

The quantity of soybean with the first grade quality level increased firstly and then decreased. Among them, the proportion and quantity in 2015 reached the maximum of $26 \%$ and 3.059 million tons. The quantity of second class soybean steadily increased with small fluctuations, and the proportion of it increased from $29 \%$ in 2011 to $54.9 \%$ in 2017 . The quantity and proportion of third grade and fourth grade experienced the stage of rising and decreasing. The maximum proportions of third grade and fourth grade in 2015 and 2016 were 38\% and $3.8 \%$ respectively. There were substandard soybeans in 2014, 2015 and 2017, accounting for $0.4 \%, 3.4 \%$ and $1.1 \%$ of the total soybean production in the year. 
Table 5. Production grade of major grain varieties in China (unit: Ten thousand tons).

\begin{tabular}{|c|c|c|c|c|c|c|}
\hline variety & grade & 2011 & 2014 & 2015 & 2016 & 2017 \\
\hline \multirow{6}{*}{ wheat } & first grade & 4343.83 & 5780.34 & 5962.48 & 5965.52 & 5671.12 \\
\hline & second grade & 4109.03 & 3609.56 & 3723.30 & 3749.39 & 4087.88 \\
\hline & third grade & 2465.42 & 1817.40 & 1874.67 & 1919.79 & 2141.27 \\
\hline & fourth grade & 587.00 & 782.49 & 807.15 & 734.42 & 726.73 \\
\hline & fifth grade & 234.80 & 959.18 & 989.41 & 335.00 & 246.57 \\
\hline & substandard & 65.74 & 239.80 & 247.35 & 180.38 & 103.82 \\
\hline \multirow{6}{*}{ corn } & first grade & 8675.15 & $14,534.56$ & $14,219.18$ & $16,707.87$ & $17,482.85$ \\
\hline & second grade & 7518.46 & 5563.67 & 6446.93 & 3842.15 & 5385.01 \\
\hline & third grade & 2506.15 & 1315.44 & 1639.81 & 1317.31 & 1401.58 \\
\hline & fourth grade & 385.56 & 129.39 & 134.78 & 65.87 & 245.89 \\
\hline & fifth grade & 192.78 & 21.56 & 22.46 & 0.00 & 73.77 \\
\hline & substandard & 0.00 & 0.00 & 0.00 & 0.00 & 0.00 \\
\hline \multirow{6}{*}{ soybean } & first grade & 11.59 & 226.06 & 305.90 & 283.40 & 230.40 \\
\hline & second grade & 420.07 & 449.70 & 345.00 & 444.60 & 790.56 \\
\hline & third grade & 506.99 & 354.90 & 384.10 & 497.90 & 313.92 \\
\hline & fourth grade & 260.74 & 138.56 & 75.90 & 49.40 & 61.92 \\
\hline & fifth grade & 72.43 & 41.32 & 0.00 & 24.70 & 27.36 \\
\hline & substandard & 0.00 & 4.86 & 39.10 & 0.00 & 15.84 \\
\hline \multirow{6}{*}{ rice } & first grade & 5125.52 & 7682.08 & 9370.13 & 7537.53 & 7122.32 \\
\hline & second grade & 8944.54 & 8673.31 & 8183.25 & 8479.73 & 8081.70 \\
\hline & third grade & 4020.02 & 3262.82 & 2561.17 & 3613.46 & 4046.06 \\
\hline & fourth grade & 1306.51 & 743.43 & 353.98 & 776.53 & 1001.09 \\
\hline & fifth grade & 402.00 & 144.56 & 249.87 & 196.72 & 417.12 \\
\hline & substandard & 301.50 & 144.56 & 104.11 & 103.54 & 187.70 \\
\hline
\end{tabular}

Note: The date source of Tables 5-7 is National Food and Material Reserve Bureau of China and Chinese Grain Network.

The number of the first grade rice rised firstly and decreased later, and the proportion reaches the maximum of $45 \%$ in 2015 . The rice of second grade quantity has a downward trend in small fluctuations, and its proportion has dropped from $44 \%$ in 2011 to $38 \%$ in 2017 . The proportion and quantity of third grade declined with small fluctuations, the proportions of fourth grade and fifth grade fluctuated between $0.5 \%-1.5 \%$ and $0.7 \%-2 \%$. The proportion of the substandard declined with small fluctuations.

\subsection{Division and Analysis of Demand Quality Grade}

Demand determines production, and high-quality markets enable producers to see the business opportunities and planting hopes. High-quality grain can be 
sold at better prices and larger sales, which can greatly increase producers' profits. Under the urging of economic interests, producers can improve the quality of grain from all aspects in the production. Therefore, the classification of the grain demand is conducive to allowing producers to see the gap in production, promoting changes in production methods, improving the quality of grain production, and providing a theoretical basis for the government to further improve the quality of grain production.

Grain demand can be divided into two major categories, four major varieties and four major uses in China. The two categories refer to food for grain and non-food for grain. Food for grain refers to the direct and indirect need to meet people's food and food consumption. Food for grain includes two categories: ration and feed grain. Non-food grain mainly includes industrial grain and seed grain. Four major varieties refer to wheat, corn, rice and soybean. The demand for these four categories accounts for $90 \%$ of the total grain demand.

Ration is the largest grain use in China, accounting for more than $50 \%$ of the total grain demand. The proportion of grain demand has been decreasing. With the improvement of people's living standards, the improvement of dietary structure, the increase of food such as meat, poultry, eggs, vegetables and fruits, the per capita consumption of rations in China has decreased significantly. It has dropped from $51.24 \%$ in 2008 to $42 \%$ in 2017 . Due to the particularity of the rations requirements, this paper classifies the ration requirements of the four main grain varieties into the level of higher than third grade. Feed grain is the second largest grain demand in China. With the improvement of people's living standards, the proportion of quantity has increased steadily. Feed grain increased from 129.12 million tons in 1995 to 163.43 million tons in 2017. Since the grain grade requirements of feed grain are not so high, this paper divides the requirements of feed demand into third class and below standards. Industrial food refers to the general term of grain used as the main raw material or excipient, such as pharmaceutical and chemical industry, alcohol, liquor making, starch and other production industries. As the third largest use of grain in China, its quantity and proportion ranked third in total grain consumption from 73.5 million tons in 2008 to 186.05 million tons in 2017, it increased more than doubled, with an average annual growth rate of $15.3 \%$. Due to the characteristics of the industry's qualified varieties in the industry, $60 \%, 10 \%, 20 \%$, and $30 \%$ of the grain varieties used for industrial of wheat, corn, soybean and rice are selected for level of higher than third grade by consulting relevant literature [12] [13] [14] [15].

Through the review and calculation of data, the grain demand for four main grain varieties and the demand grade in 2011, 2014-2017 are shown in Table 6 and Table 7.

It can be seen from Table 6 that the demand for wheat ration is gradually decreasing from 2014 to 2017 but not very large, industrial grain is rising in small fluctuations. The demand for feed grain is declining, but basically stable at 6 million tons, indicating that the planting area of wheat is basically stable. The demand for rations in rice showed a downward trend with fluctuations, and the 
Table 6. Demand for various uses of major grain varieties in China (unit: Ten thousand tons).

\begin{tabular}{|c|c|c|c|c|c|c|}
\hline Variety & uses & 2011 & 2014 & 2015 & 2016 & 2017 \\
\hline \multirow{4}{*}{ wheat } & ration & 8200 & 8500 & 8400 & 8400 & 8350 \\
\hline & $\begin{array}{c}\text { industrial } \\
\text { grain }\end{array}$ & 1140 & 1215 & 1200 & 1200 & 1250 \\
\hline & feed grain & 1700 & 1500 & 800 & 1200 & 980 \\
\hline & seed grain & 625 & 550 & 560 & 600 & 615 \\
\hline \multirow{4}{*}{ corn } & ration & 1325 & 1065 & 1092 & 1150 & 1150 \\
\hline & $\begin{array}{l}\text { industrial } \\
\text { grain }\end{array}$ & 5750 & 4000 & 4300 & 5400 & 7800 \\
\hline & feed grain & 11200 & 11650 & 12220 & 13000 & 13800 \\
\hline & seed grain & 400 & 480 & 500 & 460 & 450 \\
\hline \multirow{4}{*}{ soybean } & ration & 1100 & 1150 & 1250 & 1350 & 1500 \\
\hline & $\begin{array}{l}\text { industrial } \\
\text { grain }\end{array}$ & 5900 & 7100 & 7400 & 8100 & 8550 \\
\hline & feed grain & 30 & 150 & 150 & 250 & 300 \\
\hline & seed grain & 70 & 60 & 58 & 75 & 78 \\
\hline \multirow{4}{*}{ rice } & ration & 16055 & 16200 & 16440 & 16375 & 16514 \\
\hline & $\begin{array}{l}\text { industrial } \\
\text { grain }\end{array}$ & 1350 & 1310 & 1085 & 1135 & 1005 \\
\hline & feed grain & 1675 & 1655 & 1430 & 1410 & 1263 \\
\hline & seed grain & 430 & 430 & 500 & 510 & 560 \\
\hline
\end{tabular}

Table 7. Main grain varieties' demand grade in China (unit: Ten thousand tons).

\begin{tabular}{ccccccc}
\hline \multirow{2}{*}{ variety } & demand grade & 2011 & 2014 & 2015 & 2016 & 2017 \\
\hline \multirow{2}{*}{ wheat } & above third grade & 9395 & 9658 & 9800 & 9720 & 9840 \\
& Third class and below & 2270 & 2108 & 1280 & 1680 & 1480 \\
\multirow{2}{*}{ corn } & above third grade & 8595 & 6710 & 7114 & 8310 & 10780 \\
& Third class and below & 10080 & 10485 & 10998 & 11700 & 12420 \\
soybean & above third grade & 2350 & 2630 & 2788 & 3045 & 3288 \\
& Third class and below & 4750 & 5830 & 6070 & 6730 & 7140 \\
rice & above third grade & 16890 & 17023 & 17266 & 17226 & 17376 \\
& Third class and below & 2620 & 2572 & 2190 & 2205 & 1967 \\
\hline
\end{tabular}

amount of grain used for industry and feed increased obviously. As the main force of feed grain and industrial grain, the increase of Industrial and feed grain shows that the development of industry and feeding industry have been rapidly grown in recent years, and the demand for seed grain increased firstly and declined then, indicating the effect of various adjustment structures such as supply-side reform policy in recent years. Since people's living standards have 
improved in recent years, the demand for four uses of soybeans is growing rapidly. Rice is the main edible grain in China, the proportion and quantity of ration demand are increasing in recent years.

As can be seen from Table 5 and Table 7, the demand for wheat above medium is always greater than its production, and the gap is gradually reduced. However, there is still a demand gap of nearly 1 million tons of high-quality wheat by 2017, indicating that we should pay more attention to the cultivation of high-quality wheat. The production of wheat at the third and below the third grade is far greater than the demand, and the supply and demand gap is getting bigger and bigger. For the balance of production and demand quality of corn, the supply of medium and above grade is far greater than the demand, and the gap firstly rises and then falls, while the demand below the third level is far more than the supply. It shows that due to the high economical efficiency of corn and short cycle, the enthusiasm of growers for corn planting is greater than other crops. The production of high quality corn is more than demand. Therefore the production structure of corn and other varieties should be adjusted to reasonably inhibit corn production. For soybean, both the demand for high-quality soybean and the low grade soybean are much larger than their yield, and the gap between production and demand is increasing. Its demand for high-quality soybean is growing at an average annual rate of $8.7 \%$, while its annual production growth rate is only $2.6 \%$, far less than the growth rate of demand, and there is a gap of about 20 million tons in quantity. In terms of rice, the demand for high quality rice above medium is greater than its supply, and the gap has waved from 281.994 million tons in 2011 to 28.79 million tons in 2015 and to 217.15 million tons in 2017. The production of medium and below rice is much larger than its demand. Total amount of rice can maintain the basic balance of production and demand, but the quantity of high quality rice is still in short supply.

\subsection{Grain Supply and Demand Quality Grade Balance Prediction}

Due to the difficulty of obtaining data on grain production and demand quality grade, data interruption, and fewer samples. According to the modeling principle of grey non-equidistance $\mathrm{GM}(1,1)$, this paper predicts the quantity grade of grain production and demand according to the estimating method and Delphi method. The prediction results are shown in Table 8.

It can be seen from the forecast results in Table 8 that the total yield of wheat, corn and rice can meet the demand in the total quantity. For soybean, the total production is still far from its demand. However, in terms of the balance of supply and demand at various grades, the yield of medium and above wheat and its demand have an annual average gap of 10 million tons, and the yield of third grade and below is oversupply. In the case of corn, the above mentioned production amount is greater than its demand, the production amount is about twice than the demand. The average annual gap is more than about 14 million tons, and the gap is gradually increasing. The supply of quality grades less than third 
Table 8. Forecast of the balance of supply and demand quality of major grain varieties in China (unit: Ten thousand tons).

\begin{tabular}{|c|c|c|c|c|}
\hline variety & quality grade & 2018 & 2019 & 2020 \\
\hline \multirow{6}{*}{$\begin{array}{l}\text { production of } \\
\text { wheat }\end{array}$} & first grade & 5971.60 & 5974.65 & 5977.70 \\
\hline & second grade & 3826.73 & 3866.02 & 3905.71 \\
\hline & third grade & 2263.83 & 2423.99 & 2595.48 \\
\hline & fourth grade & 677.95 & 642.35 & 608.62 \\
\hline & fifth grade & 210.90 & 141.00 & 94.26 \\
\hline & substandard & 75.85 & 51.05 & 34.35 \\
\hline \multirow{2}{*}{ demand of wheat } & above third grade & 9871.49 & 9918.74 & 9966.21 \\
\hline & Third class and below & 1271.99 & 1153.29 & 1045.66 \\
\hline \multirow{6}{*}{$\begin{array}{l}\text { production of } \\
\text { corn }\end{array}$} & first grade & 6497.66 & 6467.71 & 6437.90 \\
\hline & second grade & 1489.39 & 1583.59 & 683.75 \\
\hline & third grade & 1219.66 & 1119.27 & 1027.14 \\
\hline & fourth grade & 249.66 & 320.82 & 412.24 \\
\hline & fifth grade & 103.52 & 229.67 & 326.99 \\
\hline & substandard & 0.00 & 0.00 & 0.00 \\
\hline \multirow{3}{*}{ demand of corn } & above third grade & $13,126.21$ & $16,262.39$ & $20,147.87$ \\
\hline & Third class and below & $13,123.80$ & $13,896.98$ & $14,715.72$ \\
\hline & first grade & 330.12 & 364.50 & 402.47 \\
\hline \multirow{5}{*}{$\begin{array}{l}\text { production of } \\
\text { soybean }\end{array}$} & second grade & 567.96 & 730.95 & 940.6944, \\
\hline & third grade & 340.40 & 314.87 & 291.25 \\
\hline & fourth grade & 48.31 & 42.65 & 37.66 \\
\hline & fifth grade & 17.52 & 15.70 & 14.07 \\
\hline & substandard & 0.00 & 0.00 & 0.00 \\
\hline \multirow{3}{*}{$\begin{array}{l}\text { demand of soy- } \\
\text { bean }\end{array}$} & above third grade & 3540.06 & 3820.70 & 4123.59 \\
\hline & Third class and below & 7675.66 & 8244.89 & 8856.33 \\
\hline & first grade & 7130.04 & 6836.89 & 6555.78 \\
\hline \multirow{5}{*}{$\begin{array}{l}\text { production of } \\
\text { rice }\end{array}$} & second grade & 8250.61 & 8155.12 & 8044.79 \\
\hline & third grade & 4259.15 & 4549.33 & 4859.28 \\
\hline & fourth grade & 1279.31 & 1357.56 & 1454.27 \\
\hline & fifth grade & 121.83 & 137.56 & 155.42 \\
\hline & substandard & 102.97 & 102.41 & 101.8484, \\
\hline \multirow{2}{*}{ demand of rice } & above third grade & 17478.68 & 17582.29 & 17686.51 \\
\hline & Third class and below & 2220.09 & 2235.30 & 2250.61 \\
\hline
\end{tabular}

is much smaller than its demand. For rice, its third grade production is not enough to supply its demand, the annual average gap is 25 million tons, increasing at a rate of 5 million tons per year. The supply of third grade and below is far 
greater than demand, and it is increasing at a rate of $2 \%$ every year. When it comes to soybean, the yield is much smaller than the demand in both the total amount and the various quality grades. The demand for third grade soybean is 3.4 times that of the supply, and the demand for below third grade per year is 21.7 times of the supply.

\section{Conclusions}

Based on China's requirements for various grain quality standards and grey non-equidistance $\operatorname{GM}(1,1)$ model and estimating method, this paper classifies and predicts the quality grades of production and demand of four major grain varieties in China. From the analysis and prediction results, we can find that the supply and demand of wheat, corn and rice can achieve a basic balance in quantity, but wheat is difficult to achieve high quality supply and demand balance. There is a big gap between supply and demand of soybean's quantity and quality. In this regard, it can be promoted from the following aspects.

On the one hand, the government can mobilize the enthusiasm of farmers to grow high-quality grain, introduce policies to encourage the improvement of the quality of wheat, rice and soybean. Agricultural subsidies should be tilted towards these high-quality grain growers and increase the subsidies. We can also establish special high-quality grain special funds to subsidy new varieties of high-quality grain and new technologies. At the same time, we ought to actively explore technological innovation, increase research and development of new varieties with high-quality, promote the transformation of scientific and technological achievements, and enhance the application of science and technology. In addition, the management of cultivated land quality should be strengthened at the same time. The quality of cultivated land is the key to producing high quality grain. Local governments should carry out large-scale political work on land development, promote the transformation of low- and medium-yield fields, increase the construction of farmland for drought and flood protection, and implement comprehensive management to improve the quality of cultivated land.

\section{Acknowledgements}

The work was supported in part by the Soft-science Foundation of Henan Province (172400410015); Philosophy and Social Science Program of Henan Province (2016BJJ022).

\section{Conflicts of Interest}

The authors declare no conflicts of interest regarding the publication of this paper.

\section{References}

[1] Xie, G., Cheng, S.K., Xiao, Y., Lu, C.X., Liu, X.J. and Xu, J. (2017) The Balance between Grain Supply and Demand and the Reconstruction of China's Food Security 
Strategy in the New Period. Journal of Natural Resources, 32, 895-903.

[2] Hu, T., Ju, Z.S. and Zhou, W. (2016) Regional Pattern of Grain Supply and Demand in China. Acta Geographica Sinica, 71, 1372-1383.

[3] Gao, L.W., Xu, Z.R., Cheng, S.K., Xu, S.W., Zhang, X.Z., Sun, W., Wu, J.X., Qu, Y.H., and Ma, J. (2016) Research on the Status of Food Security in Tibet and the Relationship between Main Grain Supply and Demand. Journal of Natural Resources, 71, 1372-1383.

[4] Teng, H., Lv, N.J. and Zhan, S. (2016) Analysis of Chongqing Grain Supply and Demand and Safety Evaluation under the New Normal. China Statistics, 71, 1372-1383.

[5] Shang, L. and Li, R.R. (2017) Influence of International Grain Price Volatility on the Balance of Grain Supply and Demand in China. Journal of Natural Resources, 30, 93-96.

[6] Zhu, H.Y., Xiao, G.A. and Wang, W.T. (2017) Government Responsibility System of Grain Quality Safety in China. Journal of Hunan University of Science \& Technology (Social Science Edition), 20, 113-121.

[7] Zhang, Q.E. (2016) Study on Grain Quality Safety under "New Normality" in China. Science and Technology of Cereals, Oils and Foods, 24, 1-5.

[8] Guo, J. and Ren, J.C. (2011) Study on the Effect Degree of Improved Seed Subsidies on Food Quality. Economic Review, No. 08, 86-89.

[9] Liu, S.F., Luan, Y.C. and Ma, Y.H. (2018) Modeling Method of Non-Equidistant $\operatorname{GM}(1,1)$ Model Based on Interpolation. Journal of Shandong University of Science and Technology (Natural Science), 37, 20-25+72.

[10] Zhang, K., Wang, C.Y. and He, L.J. (2017) An Improved Non-Equidistant Grey Model and Its Application. Chinese Journal of Engineering Mathematics, 34, 124-134.

[11] Liu, S.F., Yang, Y.J. and Jeffrey, F. (2017) Grey Data Analysis: Methods, Models and Applications. Springer Singapore, Britain.

https://doi.org/10.1007/978-981-10-1841-1

[12] Wang, J.R. and He, P.M. (2016) Research on Influence of China's Grain Consumption Structure on Grain Import Trade. Prices Monthly, No. 06, 51-54.

[13] Yuan, Y., Song, J.J., Yang, C.H. and Liu, A.H. (2018) Analysis of Grain Consumption from the Perspective of Balanced Dietary Pattern-A Case Study of Hebei Province. Cereals \& Oils, 31, 17-19.

[14] Wu, S.L., Wang, X.Z. and Gao, F. (2016) Analysis of Factors Affecting International Food Supply and International Food Demand Fluctuation. Statistics \& Decision, 20, 171-174.

[15] Wu, J.S., Jiang, P.P., Huang, X.L., Peng, J. and Wang, Z. (2013) Spatial-Temporal Analysis of Grain Supply and Demand in Rapid Urbanization Regions in Eastern China: A Case Study of Guangdong Province. Journal of Natural Resources, 28, 253-265. 